\title{
An Electrophysiological Analysis of the Time Course of Conceptual and Syntactic Encoding during Tacit Picture Naming
}

\author{
Bernadette M. Schmitt ${ }^{1,3}$, Kolja Schiltz ${ }^{2}$, Wanda Zaake ${ }^{2}$, Marta Kutas ${ }^{3}$, \\ and Thomas F. Münte ${ }^{2,4}$
}

\begin{abstract}
A central question in psycholinguistic research is when various types of information involved in speaking (conceptual/ semantic, syntactic, and phonological information) become available during the speech planning process. Competing theories attempt to distinguish between parallel and serial models. Here, we investigated the relative time courses of conceptual and syntactic encoding in a tacit picture-naming task via event-related brain potential (ERP) recordings. Participants viewed pictures and made dual-choice go/no-go
\end{abstract}

\section{INTRODUCTION}

In studying language processing, psycholinguists inquire as to "what" sorts of information the brain processes, and "when" this information is processed. Within models of speech production, it is generally assumed that going from an idea to an utterance involves knowledge at the conceptual, the syntactic, and the phonological levels of processing. Consider, for example, what takes place when a speaker wishes to describe a scene wherein a light motor bike is located next to a heavy one. According to Jackendoff (1999, see also Levelt, Roelofs, \& Meyer, 1999; Bierwisch \& Schreuder, 1992), planning this utterance involves building a conceptual structure from constituents that carry information about the situation, the event, the state, and/or the place. In the sentence "the light motor bike is beside the heavy motor bike," for instance, the situation is in the "present," there is information about objects with properties "light, heavy," and about place ('beside"). Conceptual structure also carries information about the relations between concepts such as the function-argument structure of "be," which in our example maps the objects, and the place into a state (" $x$ " is beside " $y$ '). It is to this type of information that we refer when we speak of the conceptual level. Following Jackendoff, we

\footnotetext{
${ }^{1}$ Maastricht University, ${ }^{2}$ University of California San Diego,

${ }^{3}$ Medizinische Hochschule Hannover, Otto-von-Guericke-Universität Magdeburg
}

decisions based on conceptual features (whether the depicted item was heavier or lighter than $500 \mathrm{~g}$ ) and syntactic features (whether the picture's German name had feminine or masculine syntactic gender). In support of serial models of speech production, both the lateralized readiness potential, or LRP (related to response preparation), and the N200 (related to response inhibition) measures indicated that conceptual processing began approximately $80 \mathrm{msec}$ earlier than syntactic processing.

assume that the information about an object's weight is encoded as one of its properties at the conceptual level.

At the syntactic level, information about word class, tense, number, or syntactic gender is accessed and is built into a sentence structure (see Bock \& Levelt, 1994, for details). Finally, at the phonological level, information about the phonological form of a word and a sentence becomes accessed, including morphological, segmental, syllabic, and prosodic structure (see Levelt, 1989; Levelt et al., 1999; Dell, 1986, 1988).

These processing levels are considered distinct based on tip-of-the-tongue phenomenon (for a review, see Brown, 1991), investigations of brain-damaged individuals (Miozzo \& Caramazza, 1997; Rapp \& Caramazza, 1995; Garrett, 1992, 1995), speech errors (e.g., Dell, 1986, 1990), and reaction times (Peterson \& Savoy, 1998; Levelt et al., 1991a, 1991b; Schriefers, Meyer, \& Levelt, 1990) as well as electrophysiological data from intact individuals (Schmitt, Münte, \& Kutas, 2000; Van Turennout, Hagoort, \& Brown, 1997, 1998).

In order to speak fluently, these different types of knowledge about words must be accessed at very high speeds. Thus, one central research question is "when" information about a word's concepts, syntax, and phonology actually becomes available in real time. Behavioral data have been taken to suggest that a word's conceptual/semantic and syntactic properties are retrieved before its phonological form is available (Peterson \& Savoy, 1998; Dell \& O'Seaghdha, 1991, 1992; 
Levelt et al., 1991a; Schriefers et al., 1990). Electrophysiological studies using the lateralized readiness potential (LRP) and the N200 (a component related to response inhibition) have supported this processing sequence. Specifically, electrophysiological data indicate that conceptual/semantic information is encoded about 90 to $120 \mathrm{msec}$ prior to phonological information (Schmitt et al., 2000; Van Turennout et al., 1997), and that syntactic encoding precedes phonological encoding by about 40 msec (Van Turennout et al., 1998).

In contrast to the large body of research on the relative time courses of conceptual/semantic versus phonological retrieval, and syntactic versus phonological retrieval, there are no on-line studies of the time courses of conceptual versus syntactic encoding. The theoretical views on the temporal processing of prelinguistic concepts and their linguistic syntactic realization fall into two general categories. In a prototypical serial processing model, prelinguistic conceptual information, such as the abstract features of the intended meaning, is presumed to be available prior to syntactic information (Levelt et al., 1999; Bock \& Levelt, 1994). According to this view, conceptual information is encoded first and serves as the input to the formulator, which is responsible for syntactic encoding (i.e., access to word class, syntactic gender).

On an alternative view, conceptual and syntactic information processing are not serial but rather proceed hand in hand with both types of information available simultaneously. In Jackendoff's (1999) formulation, although syntactic structures and conceptual structures are generated by independent formation rules, there are also rules interfacing the two. An example of such a rule is one specifying how a syntactic verb-to-object relation maps to a conceptual action-to-patient relation. For example, parsing the sentence "the aardvark was bitten by the ant" requires some sort of mapping indicating that the sentence object (the ant) is not acted upon, but is the actor. Of course, this would be a different mapping in the case of an active sentence, such as "the ant bites the aardvark," wherein the syntactic object is the conceptual patient. According to some theories of language comprehension (see, e.g., Cutler \& Clifton, 1999), this syntactic/conceptual integration takes place at the same time, that is, as the listener is recognizing the word. On the assumption that this type of interactive process occurs in language production as well, conceptual and syntactic information would have to be available at the same time rather than in sequence (see Figure 1 for a simplified version of a parallel and a serial processing model). The main aim of the present experiment was to seek evidence for or against the relative timing of the conceptual and syntactic encoding aspects of these two classes of language processing models.

Previous work has shown the N200 and the LRP to be especially useful in investigating the time course of information processing. The peak latency of the N200
Serial Processing

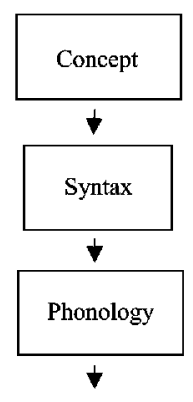

Articulation Time

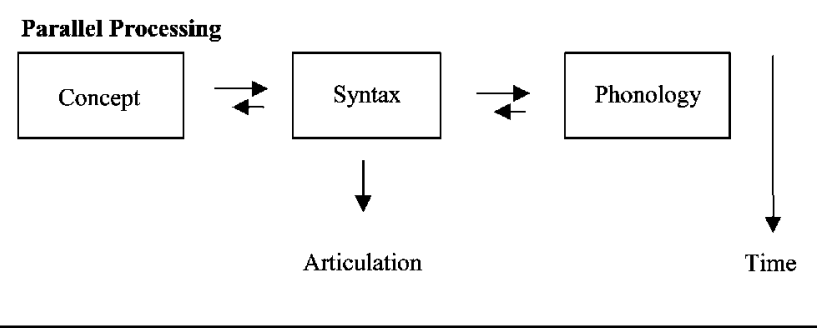

Figure 1. An illustration of parallel processing (after Jackendoff, 1999) and serial processing (after Bock \& Levelt, 1994) of conceptual, syntactic, and phonological processing. Arrows indicate information flow.

component has proven to be a sensitive index of the timing of information processing during semantic and phonological encoding (Schmitt et al., 2000). Here, we use the N200 and the LRP to examine the relative time course of conceptual and syntactic encoding during tacit picture naming, an act we assume to involve planning processes similar to those used in overt language production.

\section{The N200}

In a go/no-go paradigm, an N200 is elicited when a person withholds a response. When an individual is asked to respond to one class of stimuli (go trials) and to withhold responses to another class of stimuli (no-go trials), the event-related potential (ERP) on no-go (relative to go) trials is characterized by a large negativity $(1-4 \mu \mathrm{V})$ between 100 and $300 \mathrm{msec}$ after stimulus onset (N200), especially over fronto-central sites (Thorpe, Fize, \& Marlot, 1996; Sasaki, Gemba, Nambu, \& Matsuzaki, 1993; Gemba \& Sasaki, 1989; Kok, 1986; Pfefferbaum, Ford, Weller, \& Kopell, 1985; Simson, Vaughan, \& Ritter, 1977). It has been suggested that size of the N200 is a function of neuronal activity required for "response inhibition" (Sasaki \& Gemba, 1993; Jodo \& Kayama, 1992).

The presence of an N200 under these circumstances implies that the information, which is used to determine whether or not a response is to be given, must have been analyzed, that is, was available. Thus, a researcher 
can vary the nature of the information on which a go/nogo decision is based, and use the peak latency of the N200 effect (difference between go and no-go ERP) as an upper estimate of the time by which the specific information must have been encoded.

Schmitt et al. (2000) used this logic to examine the time course of semantic and phonological encoding as participants viewed simple line drawings on which they performed a dual-choice go/no-go task. In one condition, participants were asked to prepare a left/right-hand button press contingent on semantic information (i.e., whether the picture was that of an animal or object) and to make a go/no-go decision based on phonological information (i.e., press the button [go] whenever the name of the picture starts with a vowel sound, do not respond [no-go] whenever the name starts with a consonant sound). In another condition, the instructions were reversed: The left/right-hand response was contingent on phonological information, whereas the go/no-go response was contingent on semantic information. Schmitt et al. observed an enhanced N200 for no-go trials relative to go trials. Moreover, when the go/no-go decision was based on semantic information, the N200 effect reached its maximum peak around $380 \mathrm{msec}$ after picture onset whereas when the go/no-go decision was based on phonological information, the N200 effect peaked later ( $\sim 70 \mathrm{msec})$. Taking the peak latency of the N200 effect as the moment in time when sufficient information is available to decide whether or not to respond, we concluded that semantic information was available about $90 \mathrm{msec}$ earlier than phonological information. This difference was not observed in the reaction times on go responses, which did not differ statistically. These N200 data thus demonstrated that the electrophysiological measure is indeed very sensitive to early, fine-grained processing differences in this task, among others.

The present investigation targets the temporal course of the availability of conceptual and syntactic information during tacit naming in a similar fashion by making the go/no-go decision contingent on each in turn. By comparing the relative latencies of the two N200 effects, it will be possible to determine whether conceptual encoding precedes, follows, or is coincident with syntactic encoding.

\section{The LRP}

The LRP is derived from the readiness potential (RP, Kornhuber \& Deecke, 1965) that precedes voluntary hand movements. In contrast to the RP, the LRP is usually computed time-locked to the stimulus to which the response is given. By averaging the lateralized activity to responses made with the left and right hand (given contralateral vs. ipsilateral recording), any asymmetry that is not related to response preparation cancels out. The LRP is presumed to reflect the average amount of lateralization specifically related to the motor preparation of the responding hands, with larger amplitudes seen over the motor cortex of the hemisphere contralateral to the response (e.g., Kutas \& Donchin, 1974). The LRP allows researchers to see motor-related brain activity prior to an overt or go response (Mulder, Wijers, Brookhuis, Smid, \& Mulder, 1994; Miller, Riehle, \& Requin, 1992). Perhaps more importantly, the LRP also reveals motor activation in the "absence" of any overt response. That is, the LRP reflects preparation to respond, even when the response is not executed as in the case of no-go trials (cf. Osman, Bashore, Coles, Donchin, \& Meyer, 1992). These characteristics make the LRP a suitable brain measure for studying the time course of information encoding, such as during speech planning and production (Schmitt et al., 2000; Van Turennout et al., 1997, 1998).

\section{The Experimental Paradigm}

The experiment was carried out in German. In an initial practice session, participants were asked to name a series of pictures, in order to make sure that they knew their intended names, which were then used during the recording session. During the ERP recording session, participants were asked to make a dual decision, that is, classifying the pictures with respect to both a conceptual and a syntactic feature.

The conceptual decision was to determine whether the pictured object was heavier or lighter than $500 \mathrm{~g}$. This decision was assumed to involve conceptual activation of the depicted object as well as nonlinguistic information, in this case related to the weight of the object in the real world. The syntactic decision was to determine whether the depicted object's name had feminine ("die") or masculine ("der"') syntactic gender. Note that, in German, syntactic gender is independent of biological gender (see Van Berkum, 1997, for detailed information on gender access).

To ensure that the conceptual and the syntactic decisions were equally difficult, we pretested the participants with the stimulus pictures from the main experiment in two simple reaction time conditions. In one condition, participants were asked to make a simple right/left-hand decision based on conceptual information of the picture (heavier or lighter than $500 \mathrm{~g}$ ). In the other condition, participants were asked to carry out a simple right/left-hand decision based on syntactic information (masculine or feminine syntactic gender). The order of the blocks as well as the hand responses (left vs. right) was counterbalanced. The order of the items was randomized. The results showed a mean reaction time of $812 \mathrm{msec}(S D=73 \mathrm{msec}$ ) for the conceptual decision, and a mean reaction time of $842 \mathrm{msec}(S D=80 \mathrm{msec})$ for the syntactic condition. A paired sample $t$ test showed that the two conditions did not differ significantly from each other, $t(19)=1.18, p=.25$. 
In the main experiment, the instruction was, for example, "Press the left button for a light object and the right button for a heavy object. However, respond only if the picture's name has feminine gender, and not if it has masculine gender." Thus, depending on the outcome of these two decisions, a response was given with either the left or right hand, or not at all (see Figure 2 for an illustration).

In one condition, the responding hand will be contingent on conceptual information ("hand = concept") and the go/no-go decision will be contingent on syntactic information ('go/no-go = syntax"). In this case then, the timing of the N200 effect (i.e., the difference between go and no-go response) provides an upper limit on the moment in time by which the syntactic information for determining whether or not a response is to be given must be available. In the other condition, the response contingencies will be reversed; that is, the responding hand will be contingent on syntactic information ("hand = syntax"), whereas the go/no-go decision will be dependent on conceptual information ('go/ no-go $=$ concept' $t^{\prime}$. In this case then, the latency of the N200 effect can be taken as an upper limit on the availability of conceptual information. On a serial account of language production, conceptual encoding is presumed to precede syntactic encoding. It would seem then that information of a conceptual nature would be available earlier than information of a syntactic nature, regardless of the purpose for which it will be used.

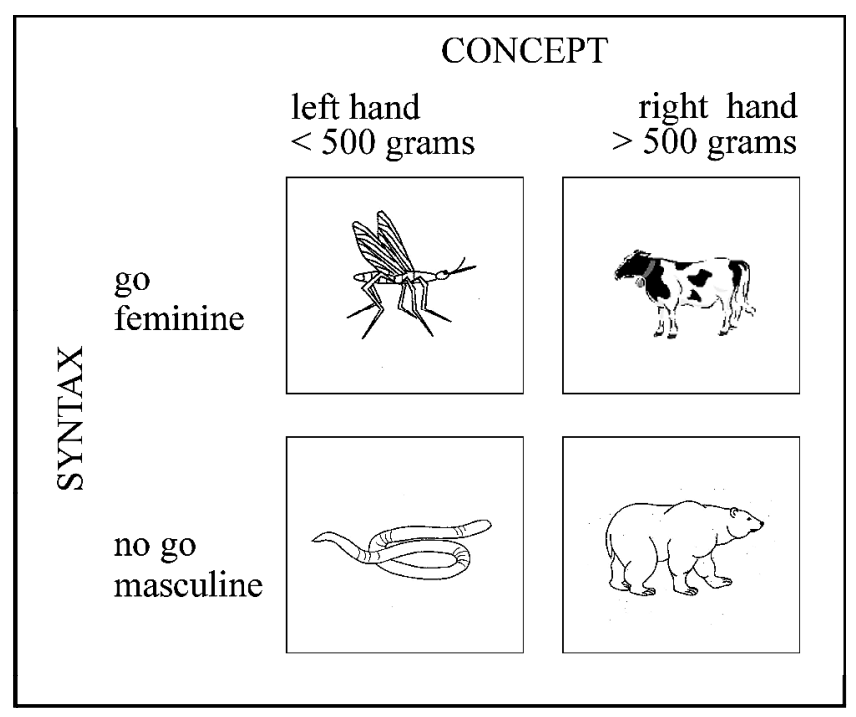

Figure 2. This illustration of the experimental design shows an example from the hand $=$ concept condition. The response hand is contingent on conceptual information. The go/no-go response is contingent on syntactic information. In the hand = syntax condition, the pictures were the same but the response contingencies were reversed: in that case, the response hand would be contingent on syntactic information, and the go/no-go response would be contingent on conceptual information (see also Appendix B for a detailed example).
Given the known relation between the N200 and withholding a response, we would expect to see this difference in information availability in an earlier N200 effect when the go/no-go decision is based on conceptual relative to syntactic information. By the same token, if conceptual and syntactic information were processed simultaneously, then we would expect to see no difference in the timing of their associated N200 effects.

A similar logic applies to the LRPs recorded in dualchoice go/no-go paradigm, albeit with respect to response preparation rather than response inhibition processes. Based on a large literature, we assume that people prepare their response with a particular hand as soon as they have some information available about which it will be, and that this motor preparation is reflected in an LRP. If the responding hand is contingent on conceptual information, and conceptual encoding precedes syntactic encoding (as assumed by serial processing accounts of language production), then an LRP should develop for both go and no-go trials alike. However, as soon as the syntactic information is encoded, indicating that no response is to be made, the LRPs for go and no-go trials should diverge from each other; specifically, the LRP for no-go trials should drop back to baseline as preparation to respond is abandoned. In contrast, when the response contingencies are reversed (i.e., the responding hand is contingent on syntactic information, and the go/no-go decision is contingent on conceptual information), no LRP should develop on no-go trials. This is expected on a serial account, because its proponents assume that the early availability of the conceptual information, indicating that no response is to be given, would effectively forestall the development of any preparation. By contrast, on a parallel processing account, partial information about whether or not a response is to be executed would be available from the beginning of processing and in both response contingency conditions. Thus, we would not expect to see a no-go LRP develop in either condition.

Note that by opting to use the dual-choice go/no-go paradigm as a means of probing language production processes we are in the position of making inferences from the ERPs prior to button presses, rather than overt naming. We, nonetheless, contend that this type of experiment provides data that are relevant to issues within language production for several reasons: (1) Pictures are the method of choice for activating information processing during language production in psycholinguistic experiments as they are thought to trigger the same encoding processes as those that occur naturally in a speaker putting an abstract idea into words (see Glaser, 1992). For example, picture primes semantically related to target pictures have been found to inhibit naming of the target pictures compared to unrelated picture primes (Tipper et \& Driver, 1988), implicating a common semantic representation for the prime and target. Moreover, in picture-word interfer- 
ence experiments (Levelt et al., 1991a), the planned but not executed naming of pictures has been shown to influence lexical decisions of target words, either semantically or phonologically. These interference effects, among other results, have been taken as evidence for the assumption that preparing to name a picture involves the same semantic and/or phonological processes as word processing. Furthermore, (2) since our participants were trained to name the pictures before the main recording session was conducted, we believe that they accessed the correct picture name in the main session as well. Although they did not say the picture's name aloud, it is generally assumed that internal speech planning mechanisms (tacit naming) are automatically activated by the presentation of the picture. In addition, (3) the correctness of the subjects' responses serves as evidence that they indeed accessed the correct underlying linguistic information, that is, the name of the picture. Finally, (4) the dual-choice go/no-go paradigm we chose to use in the present study was based on the same logic and essentially the same paradigm as that introduced by Van Turennout et al. (1997, 1998) for estimating the time course of semantic, syntactic, and phonological encoding. Although they did have participants directly name pictures on some (filler) trials, their LRP analyses and inferences were not based on data from these "naming" filler trials but rather from button presses on trials in which no direct- but only delayednaming was involved. Van Turennout et al. argued that their results applied to language production proper, that is, to intrinsic access of the picture's name upon its appearance needed to perform the required judgments. We appeal to the same logic for the LRP and N200 data reported here.

\section{RESULTS}

\section{Push-Button Reaction Times}

The mean reaction times for correct go responses in the dual-choice go/no-go task were $1001 \mathrm{msec}(S D=$ 130) for the hand = syntax condition and $1032 \mathrm{msec}$ $(S D=131)$ for the hand $=$ concept condition, $F(1,19)$ $=2.63, n s$. Incorrect responses (time-outs, i.e., reaction times longer than $1500 \mathrm{msec}$ and wrong-hand response) were excluded from the analysis. The error proportions did not differ for the two response contingencies, hand $=$ concept: $10.1 \%(S D=3.2)$, hand $=$ syntax: $9.7 \%(S D=3.3)$, according to a paired sample $t$ test, $t(19)=0.9$, ns.

\section{N200 Analysis}

We assume that the increased negativity for no-go trials in comparison to go trials reflects the moment in time by which the relevant information necessary to withhold a response must have been encoded. The time it takes to encode the relevant information might, therefore, be seen in the peak latencies of the N200 effects.

Of interest was whether the latency characteristics of the N200 effects reliably differ for the two response contingency conditions (hand $=$ concept vs. hand $=$ syntax). The ERP difference waveform "no-go minus go" was calculated for each of the conditions. Figure 3 shows grand average ERPs for 20 participants at midline sites (going from the front to the back of the head). Both response contingency conditions show an N200 effect (see left and middle column of Figure 3), with no-go trials being more negative than go trials. However, as can be seen in the difference waveforms (no-go minus go) for both conditions, the onsets and latencies of the N200 effects are strikingly different (right panel in Figure 3). The N200 effect in the "hand = syntax, go/no-go = concept" condition precedes that in the "hand = concept, go/no-go = syntax" condition.

The statistical comparison of the ERP difference waveforms at four frontal electrodes (Fp1/2, F3/4) supported the above description of the results based on visual inspection. For each participant, we measured the peak latencies of the N200 effect between 200 and $700 \mathrm{msec}$ at each frontal electrode for correct trials ( $\sim 200$ trials per condition minus errors). For the peak latencies, an ANOVA was carried out with "response preparation" (hand = concept vs. hand $=$ syntax) and "electrodes" (the four electrodes) as repeated measures factors. The main effect of "response preparation" was significant, $F(1,19)=13.73, p<.0015$, reflecting a difference in peak latencies. When the go/no-go decision is contingent on conceptual information (as it is the case for the "hand = syntax" condition), the mean peak latency of the N200 effect is $477 \mathrm{msec}(S D=128$ msec). In contrast, when the go/no-go decision is contingent on syntactic information (hand = concept), the mean peak latency of the N200 effect is $550 \mathrm{msec}$ $(S D=118 \mathrm{msec})$. The mean latency difference (across the four electrode sites) of the two N200 effects is 73 msec. Neither the main effect "electrodes" nor the interaction "electrodes $\times$ response preparation" is significant.

The lack of interaction between frontal electrodes and response preparation indicates that the two N200 effects have a similar scalp distribution, that is, are generated by the same neural populations. To see whether this was indeed the case, we compared the scalp distributions of the two N200 effects across all electrode sites, as shown in Figure 4. The scalp distributions for the conceptual and the syntactic N200 effects look very similar, and this similarity was confirmed statistically. For the analysis, a difference ERP (no-go minus go) was calculated for each of the two response-conditions for each participant. Next, grand average difference waves were created for each condition, and peak latencies of the N200 effect were 
Figure 3. Grand average ERPs $(n=20)$ on go and no-go trials in the hand = concept condition (left column) and the hand $=$ syntax condition (middle column). The ERPs were timelocked to picture onset. Both conditions are associated with a frontal negativity (N200) that is more negative for no-go than for go trials. In the right column, the "no-go minus go" difference waves (i.e., the N200 effects, interpreted as response inhibition) for the two conditions are shown superimposed. Displayed are data from 20 participants (200 trials per conjected trials) over five midline electrodes (from the front $[\mathrm{Fz}]$ to the back $[\mathrm{Pz}]$ of the head, see head icon for electrode positions). Note that the calibration bar shows $5 \mu \mathrm{V}$ for the left and middle column and 3 $\mu \mathrm{V}$ for the difference waves in the right column. Negative voltage is plotted up in this and all subsequent figures. dition per subject, minus re-

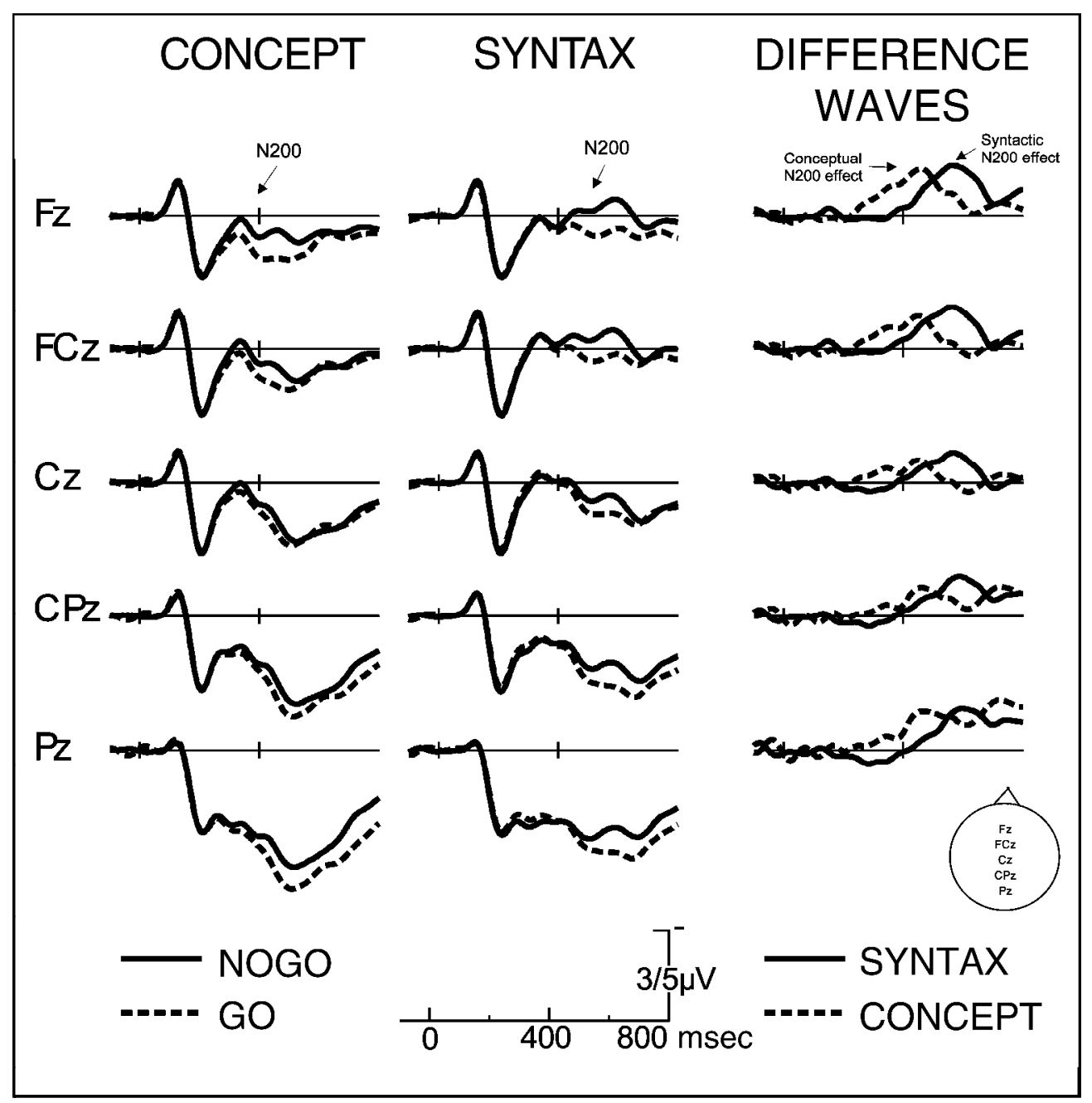

measured. We then calculated the mean amplitudes of each individual's difference wave in a time window \pm 40 around the peak latency in the grand mean, separately for each condition (i.e., for each participant we measured the mean amplitude between 420 and $500 \mathrm{msec}$ for the concept condition and between 520 and $600 \mathrm{msec}$ for the syntax condition). The resulting measures were normalized according to McCarthy and Wood (1985), and analyzed in an ANOVA with "response condition" (concept vs. syntax) and "electrodes" (30 sites) as repeated measures factors. The main effect of "response condition" was not significant. The main effect "electrodes" was significant, $F(29,551)=$ 5.0, Greenhouse-Geisser corrected $p<.01$. Most importantly, the interaction was not significant, indicating indistinguishable scalp distributions for the two N200 effects. Also clearly visible from Figure 4 is the frontal location of the effect, comparable to the data reported by Thorpe et al. (1996).

\section{LRP Analyses}

Four average LRP waveforms for each participant were calculated: (1) hand = concept, go = syntax, (2) hand = concept, no-go $=$ syntax, (3) hand $=$ syntax, go $=$ concept, and (4) hand $=$ syntax, no-go $=$ concept.

Figure 5 shows the grand average of go LRPs (top panel) and no-go LRPs (bottom panel) for the two response conditions: hand $=$ concept, and hand $=$ syntax, at middle central electrode sites (C3 and C4). The typical LRP pattern for go trials was obtained in both conditions. The beginnings of a no-go LRP, however, was discernible only in the hand = concept condition and "not" in the hand = syntax condition. The dashed vertical lines in the bottom panel of Figure 5 delimit this no-go effect.

The results of the statistical analysis support this descriptive analysis. LRPs were quantified by mean amplitude measures relative to the prestimulus baseline ( -200 to 0 msec before picture onset). Their onset latency was determined by one-tailed serial $t$ tests between 300 and $800 \mathrm{msec}$ after picture onset against zero mean. The $t$ tests were carried out stepwise with a step size of $4 \mathrm{msec}$. For each test, $40-\mathrm{msec}$ worth of data (i.e., $\pm 20 \mathrm{msec}$ around the measured point) was averaged. Onset latency was defined as the point at which four consecutive $t$ tests were significantly different from zero (in the same direction). 
The mean onset latency for the go LRPs in the hand $=$ concept condition was $472 \mathrm{msec}$ after picture onset (from that time on all $t(19)<-1.73$, all $p<.05$ ). The mean onset latency for the go LRP in the hand $=$ syntax condition was $424 \mathrm{msec}$ after picture onset (from that time on all $t(19)<-1.73$, all $p<.05)$.

Similar analyses for the onset of no-go LRPs revealed a significant divergence from baseline for the hand $=$

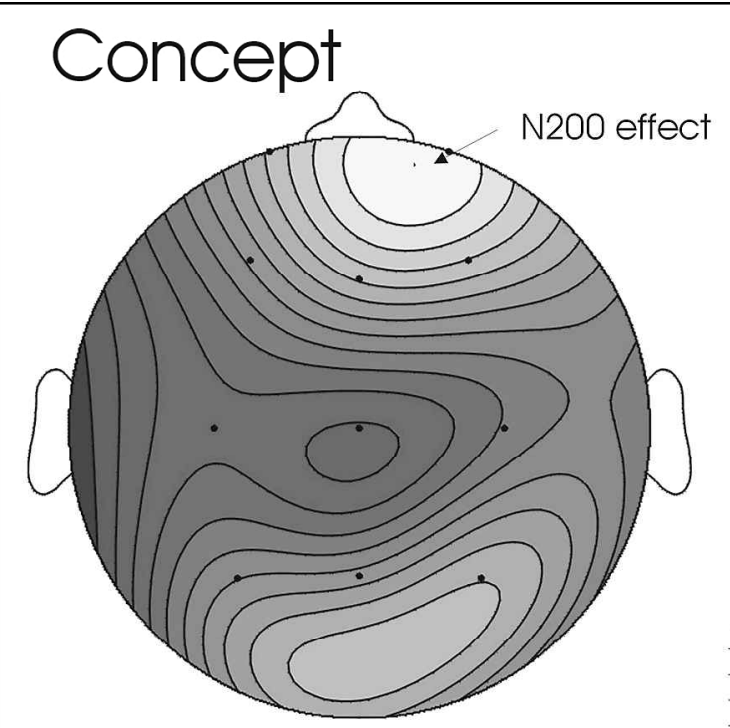

\section{Syntax}
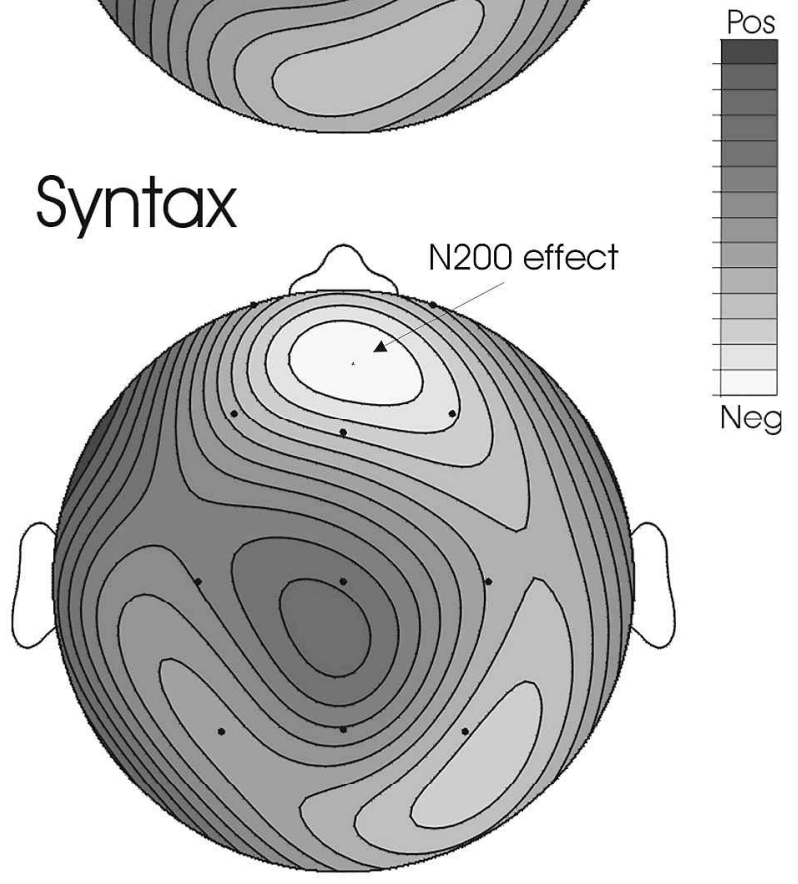

Figure 4. Scalp distribution of normalized mean voltage amplitudes of the two N200 effects. The upper panel shows the N200 effect for the go/no-go $=$ concept condition (mean amplitudes of the time window 420-500 msec after stimulus onset). The lower panel shows the N200 effect for the go/no-go = syntax condition (mean amplitudes of the time window 520-600 msec after stimulus onset). Lighter shades indicate regions of negative voltage amplitudes in the "no-go minus go" difference wave (i.e., the N200 effect). Darker shades indicate regions of positive voltage amplitudes. The electrode locations are marked by black dots. The view is from the top of the head, the triangle (nose) indicates the front of the head.

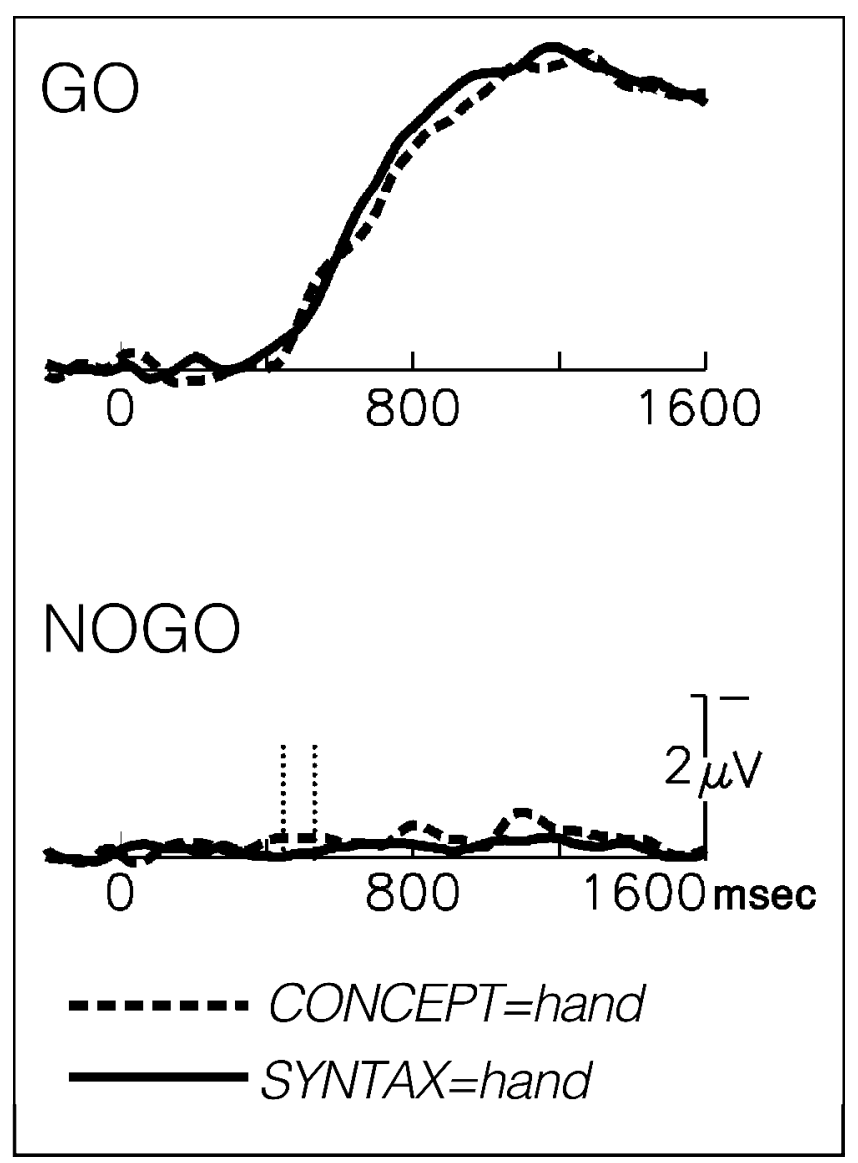

Figure 5. Grand average LRP on go trials (top panel) and no-go trails (bottom panel) in the two dual-choice tasks, involving hand preparation contingent on conceptual or on syntactic information (20 participants, 100 trials per condition, minus rejected trials). The LRP is time-locked to picture onset. The two dashed vertical lines surround the no-go effect in the hand = concept condition.

concept condition starting at $452 \mathrm{msec}$, which lasted for approximately $90 \mathrm{msec}$, until $540 \mathrm{msec}$ after picture onset (in this time interval all $t(19)<-1.73$, all $p<.05$ ). In contrast, no significant divergence from baseline was observed for the no-go LRP in the hand = syntax condition.

The two go LRPs were compared in two ways: (1) We compared the hand $=$ syntax go LRP and the hand $=$ concept go LRP via a serial paired sample $t$ test and found no significant differences over the entire recording epoch. (2) We also carried out a fractional peak analysis in order to make the LRP onset analysis comparable to that for the N200 peak. First, per participant and per condition, we defined the onset of the LRP as the moment at which the go LRP reached the $15 \%$ of its peak (maximum) amplitude. This method revealed a mean onset latency for the hand $=$ concept go LRP of $534 \mathrm{msec}(S D=101 \mathrm{msec})$ and for the hand = syntax go LRP of $555 \mathrm{msec}(S D=82 \mathrm{msec})$. When compared via a paired sample $t$ test, these two go LRP onset latencies were not significantly different. 


\section{DISCUSSION}

In this study, we used the high temporal resolution of electrophysiological measures to estimate the relative time courses of conceptual and syntactic encoding during tacit picture naming. The availability of these two kinds of information was measured by means of two different ERP components- the N200 and the LRP- in a dual-choice go/no-go decision task. Our results clearly showed that under these conditions, conceptual information becomes available prior to syntactic information.

\section{$\mathbf{N 2 0 0}$}

Our N200 results speak to the temporal course of information flow related to response inhibition. Specifically, the N200 effect ("no-go minus go" ERPs) reflects an upper limit on the time by which information about whether an actual response needs to be made or withheld must have become available. In the extant literature on the N200 (see Introduction), this time is typically captured by the mean peak latency of the N200 effect. Here, we found that the average peak latency of the N200 effect was $73 \mathrm{msec}$ earlier when the go/no-go response was contingent on conceptual information than when it was contingent on syntactic information.

It is important to note that this difference in the peak latencies of the conceptual and syntactic N200 effects cannot be attributed to a difference in the difficulty between the two decisions. Our pretest data showed that the explicit task of conceptual categorization (i.e., deciding whether an object weighs more or less than $500 \mathrm{~g})$ took about the same amount of time as the explicit task of syntactic categorization (i.e., deciding whether an object has masculine or feminine gender) in a simple reaction time task. This result suggests that the two tasks we used in the dual-choice go/no-go paradigm were of equal difficulty. Accordingly, it cannot be argued that the conceptual and syntactic processes start in parallel, but one finishes earlier (as reflected in an earlier N200) because it is an easier decision. Rather, we maintain that the observed difference in the latency of the N200 effects reflects serial access to conceptual and syntactic information during tacit picture-naming processing.

The N200 effects in our dual-choice go/no-go task are relatively late $(\sim 477-550 \mathrm{msec}$ after stimulus onset), compared to those reported in simple go/no-go paradigms. We can only speculate here about potential reasons for this difference. Thorpe et al. (1996), for example, obtained an N200 effect based on visual processing in the simple go/no-go task around 150 msec after stimulus onset, and thus concluded that the decision was achieved in under $150 \mathrm{msec}$. The median reaction time for go responses in the Thorpe et al. study was $445 \mathrm{msec}$, approximately $300 \mathrm{msec}$ later than the peak N200 latency. Simple reaction times for the conceptual and syntactic analyses in the current study were around $800 \mathrm{msec}$. Both of these processes thus seem to be more difficult than the visual processing in the Thorpe et al. study, and not surprisingly in combination yielded somewhat longer dual-choice go responses ( $\sim 1000 \mathrm{msec})$. Naturally, conceptual and syntactic encoding can only take place after at least some initial visual processing, so we expected at least somewhat longer reaction times than Thorpe et al. It is also possible that the relatively complex dual-choice task we used placed some additional, nonspeech related, cognitive load on the participants. If this was the case, some constant delay would be added to the processing time for a trial, and we could not take the actual latencies of the N200 effects as absolute values for the speech inherent processes. However, this would not negate a relative comparison between the N200 peak latencies in the two response conditions, which clearly shows an earlier N200 for conceptually than syntactically based decisions.

\section{LRP}

In the present study, the LRP was assessed in addition to the N200 as a means of tracking the time courses of conceptual and syntactic encoding (according to the same experimental logic as in Schmitt et al., 2000; Van Turennout et al., 1997, 1998). As detailed in the Introduction, development of a no-go LRP in the hand $=$ concept condition, but not in the hand = syntax condition, was considered crucial for a serial processing account for conceptual and syntactic encoding during tacit naming. In fact, this is exactly what we found. In the hand $=$ concept condition, a modest nO-go LRPs developed for approximately $88 \mathrm{msec}$ (i.e., between 452 and $540 \mathrm{msec}$ after picture onset). We suggest that during this interval, the conceptual information served to prepare one of the hands to respond, unaffected by syntactic information, which apparently was not yet available for the go/no-go decision. However, the syntactic information necessary to favor either a go or a no-go decision seems to have become available after approximately $88 \mathrm{msec}$ or so (540 msec after picture onset), as reflected in the return of the no-go LRP to the baseline. The observed no-go LRP effect, while small $(\sim 1 / 2 \mu \mathrm{V})$, is about the same size as those reported by Van Turennout et al. (1997, 1998).

Taken together, the LRP and N200 data reveal a similar pattern of relative timing of conceptual and syntactic processing during tacit naming. Both the N200 latency data and LRP data suggest that conceptual information becomes available ahead of syntactic information by 
about $73-88 \mathrm{msec}$. As outlined in the Introduction, data of this kind are relevant to the time course of language production because they index information access during intrinsic picture name processing. Granted this link, the present data support any class of models of speech production wherein conceptual encoding begins prior to syntactic encoding; these include serial processing models (Levelt et al., 1991a, 1999) as well as various models of cascaded processing (Peterson \& Savoy, 1998; Dell \& O'Seaghdha, 1992). At the same time, these data reject parallel processing models, such as the one proposed by Jackendoff (1999).

Traditionally, the N200 and LRP are considered to be distinct ERP components, where components are defined in terms of their neural generators. For example, they differ in their distributions across the scalp; the LRP is not present at frontal sites, and the N200 is not present at central sites (see Figures 3 and 4). That said, we do not rule out the possibility of a functional dependency between the two insofar as they reflect response inhibition and response preparation processes, for example, along the lines proposed by Fuster (1997). Fuster argued that following early visual processing in the parietal and inferotemporal cortex, the processed information is evaluated by the prefrontal cortex. Our frontal N200 effect may reflect this evaluation. According to Fuster, once evaluated, the information is sent by the prefrontal cortex to the motor cortex. It is this activity that is presumably reflected in the LRP. We should not forget, however, that the N200 effect is a difference between ERPs elicited by go and no-go events whereas the go LRP reflects preparation for a movement that is eventually executed. Thus, the exact nature of the relationship between these two ERP components and their associated neural generators awaits further investigation.

In summary, two different ERP components were used to investigate the temporal course of conceptual and syntactic encoding during language processing. Specifically, we used the LRP component (related to response preparation) and the N200 effect (related to response inhibition) to monitor on-line picture processing. Both brain waves clearly show an earlier onset of conceptually based compared to syntactically based processing. Insofar as our task involves tacit picture naming (as is typically assumed), the results are relevant to theories of language production as they empirically support a serial or cascaded processing of conceptual and syntactic encoding rather than a continuous interaction of the two.

\section{METHODS}

\section{Subjects}

Twenty native speakers of German participated in the experiment (eight women, 22 to 30 years of age, mean 25). All participants were right-handed, neurologically healthy, and had normal or corrected-to-normal vision. Six other participants were excluded because of excessive artifacts (more than $30 \%$ of the trials) and technical failures.

\section{Stimuli}

The stimuli were 120 simple black-on-white line drawings consisting of two conceptual categories: 60 objects and animals that were heavier than 500 g (e.g., the picture of a cow) and 60 objects and animals that were lighter than $500 \mathrm{~g}$ (e.g., the picture of an ant). In each of the two categories, the names of half of the items had feminine syntactic gender (e.g., "die ${ }_{\mathrm{FEM}} \mathrm{Kuh}^{\prime}$ [the cow]) and the other half with masculine syntactic gender (e.g., "der ${ }_{\text {Masc }}$ Esel" [the monkey]). Twenty pictures were used as practice stimuli. The remaining 100 pictures served as the targets (25 pictures in each conceptual and syntactic condition, see Appendix A). Pictures subtended about $8^{\circ}$ of visual angle in height and $8^{\circ}$ in width (viewing distance $1.10 \mathrm{~m}$ ). The depicted items were matched on word frequency using the CELEX database (Baayen, Piepenbrock, \& Van Rijn, 1993). The mean lemma frequency (and standard deviation) per million was 55.7 (58) for the heavy/masculine category, 58.8 (80) for the heavy/feminine category, 62.6 (83) for the light/ masculine category, and 45.5 (48) for the light/feminine category. Statistically, these four groups did not differ, as shown by an ANOVA on frequency with "group" as factor, $F(3,96)=0.28$.

\section{Design}

Each participant received eight different instruction sets. In four of the instruction sets, the responding hand was contingent on conceptual information and the go/no-go decision was contingent on syntactic information, with left- and right-hand go and no-go responses counterbalanced for each item. For the other four instruction sets, the response contingencies were reversed; the responding hand was contingent on syntactic information and the go/no-go decision was dependent on conceptual information, again counterbalanced for leftand right-hand go/no-go responses for each item. Appendix $\mathrm{B}$ illustrates the eight different instruction sets and provides an example of the different responses to the same item, in this case the picture of an ant. Each picture was presented eight times to each participant, that is, once per condition. The order of conditions was randomized across participants.

\section{Procedure}

Participants were tested individually while seated in a soundproof chamber in front of a computer screen. They were first familiarized with the pictures during a practice block wherein each picture was shown with its 
name printed below it for 4 sec. In a second practice block, the pictures were repeated without their names and the participants were asked to name them aloudas fast and as accurately as possible. This procedure guaranteed that each participant knew and used the intended names of the pictures during the experimental run. Then, the reaction time pretest was carried out as described in the Introduction.

During the recording session, the participants did not name the pictures aloud, but rather performed a dualchoice go/no-go task. Because there were eight different instructions, each participant carried out eight different dual-choice tasks, one per experimental condition (see Appendix B).
Each condition began with 40 practice trials (10 pictures of each conceptual/syntactic category), followed by 100 experimental trials $(25$ pictures for each conceptual/syntactic category, presented in two blocks of 50 trials). Between blocks there was a short break. Each block started with three warm-up trials that were excluded from further analysis. The order of the instructions was randomized across participants and the sequence of pictures was randomized in every block and for every participant. Each experimental block lasted about $5 \mathrm{~min}$. The entire experiment lasted about $2 \mathrm{hr}$.

A trial began with the presentation of a fixation point in the middle of a high-resolution 21-in. computer screen. After a randomized interval of 1500 to 3000

\section{Appendix A: List of the Names of the Pictures Used in the Experiment}

Feminine Syntactic Gender

$$
<500 \mathrm{~g}
$$

Ameise (ant)

Banane (banana)

Biene (bee)

Birne (pear)

Blume (flower)

Brezel (pretzel)

Brille (glasses)

Dose (tin)

Feder (feather)

Fledermaus (bat)

Fliege (fly)

Kaulquappe (tadpole)

Kerze (candle)

Kette (necklace)

Krabbe (crab)

Libelle (dragonfly)

Maus (mouse)

Mücke (mosquito)

Pfeife (pipe)

Raupe (caterpillar)

Schere (scissors)

Schnecke (snail)

Schwalbe (swallow)

Spinne (spider)

Spritze (syringe)
$>500 \mathrm{~g}$

Achse (axle)

Ampel (traffic light)

Ananas (pineapple)

Antilope (antelope)

Ente (duck)

Fähre (ferry)

Giraffe (giraffe)

Gitarre (guitar)

Gondel (gondola)

Hyäne (hyena)

Kanone (canon)

Katze (cat)

Kommode (chest of drawers)

Kuh (cow)

Lampe (lamp)

Leiter (ladder)

Palme (palm tree)

Pyramide (pyramid)

Säge (saw)

Schaukel (swing)

Schlange (snake)

Taube (pigeon)

Torte (cake)

Trompete (trumpet)

Ziege (goat)

Masculine Syntactic Gender

$$
<500 \mathrm{~g} \quad>500 \mathrm{~g}
$$

Apfel (apple)

Ball (ball)

Ballon (balloon)

Bügel (hanger)

Drachen (kite)

Fisch (fish)

Frosch (frog)

Füller (pen)

Gürtel (belt)

Hefter (stapler)

Igel (hedgehog)

Kamm (comb)

Knopf (button)

Kreisel (top)

Löffel (spoon)

Pfeil (arrow)

Pilz (mushroom)

Rasierer (razor)

Reisverschluss (zip)

Schirm (umbrella)

Schläger (bat)

Schlüssel (key)

Schuh (shoe)

Trichter (funnel)

Wurm (worm)
Adler (eagle)

Affe (monkey)

Anker (anchor)

Bär (bear)

Brunnen (well)

Bus (bus)

Elch (moose)

Elefant (elephant)

Esel (donkey)

Flamingo (flamingo)

Gorilla (gorilla)

Hai (shark)

Hirsch (deer)

Koffer (suitcase)

Löwe (lion)

Mantel (coat)

Papagei (parrot)

Pelikan (pelican)

Pfau (peacock)

Reifen (tire)

Schwan (swan)

Strauss (ostrich)

Tiger (tiger)

Wal (whale)

Wolf (wolf) 
msec, the picture was presented in the center of the screen for $1500 \mathrm{msec}$. The picture was immediately replaced by the fixation point, indicating the start of a new trial.

Participants were instructed to rest their arms and hands on the elbow rest of the armchair and to hold their thumbs on the left and right response button. On go trials, participants responded by pressing one of the two buttons as quickly as possible. On no-go trials, they did not press any of the buttons. Participants were instructed not to speak, blink, or move their eyes while the picture was on the screen.

\section{Apparatus and Recordings}

Push-button response latencies were measured from picture onset with the time-out point (the moment in time after which responses were registered as missing) set at $1500 \mathrm{msec}$. Time-outs and errors, that is, wrong responses, were excluded from further analyses. The EEG was recorded from 30 scalp sites using tin electrodes mounted in an electrode cap with reference electrodes placed at the mastoids. Signals were collected using the left mastoid electrode as a reference and re-referenced off-line to the mean of the activity at the two mastoid processes. Blinks and vertical eye movements were monitored by electrodes placed on the right and left lower orbital ridge, also referred to the left mastoid. Lateral eye movements were monitored by a bipolar montage using two electrodes placed on the right and left external canthus. The eye movements were recorded in order to allow for later off-line rejection. Electrode impedance was kept below $5 \mathrm{k} \Omega$ for the EEG and eye-movement recording.
Signals were amplified with a bandpass from 0 to 100 $\mathrm{Hz}$ and digitized at $250 \mathrm{~Hz}$. Averages were obtained for 1048-msec epochs including a 100-msec prestimulus baseline period for the N200 component, and for the 2048-msec epoch (baseline $200 \mathrm{msec}$ ) for the LRP. Trials of correct responses were visually inspected. Trials contaminated by eye movements or amplifier blocking within the critical time window were rejected from averaging by a computer program using individualized rejection criteria. The number of rejections did not reliably differ for the two response contingency conditions. On average, $19 \%$ of the trials in the hand $=$ concept condition and $17 \%$ of the trials in the hand $=$ syntax were excluded from further analysis (including ERP artifacts and incorrect responses).

Both the LRP and the N200 were calculated for all electrode sites. For the LRP analysis only those electrode sites close to $\mathrm{C}^{\prime}{ }^{\prime}$ and $\mathrm{C}^{\prime}{ }^{\prime}$ were analyzed further, as these yield the largest RPs for hand movements (e.g., Kutas \& Donchin, 1974). For the N200 ERP peak analysis, only frontal electrode sites were investigated; as for these, the N200 effect is the largest (Thorpe et al., 1996). The scalp distributions of the two N200 effects were analyzed for all 30 electrodes.

\section{Acknowledgments}

The research reported in this article was supported by a postdoctoral fellowship from the San Diego McDonnell-Pew Cognitive Neuroscience Institute and a grant from the German Academic Exchange Service (DAAD) to B.M.S., DFG grant MU1311/7-1 to T.F.M., and grants HD22614 and AG08313 to M.K. We thank Antoni Rodriguez-Fornels for his comments on previous versions of the article and Henk Jansma for his graphical assistance.

\section{Appendix B: Illustration of the Eight Different Instructions for One Sample Picture of an "Ant"}

Eight different instructions (1-4: hand = concept; 5-8: hand $=$ syntax)

$1 \quad$ Press left if $>500 \mathrm{~g}$, press right if $<500 \mathrm{~g}$, press only if its name has feminine syntactic gender. Press right if $>500 \mathrm{~g}$, press left if $<500 \mathrm{~g}$ press only if its name has feminine syntactic gender.

3 Press left if $>500 \mathrm{~g}$, press right if $<500 \mathrm{~g}$, press only if its name has masculine syntactic gender.

4 Press right if $>500 \mathrm{~g}$, press left if $<500 \mathrm{~g}$, press only if its name has masculine syntactic gender.

5 Press right if feminine, press left if masculine, press only if $<500 \mathrm{~g}$.

6 Press right if masculine, press left if feminine, press only if $<500 \mathrm{~g}$.

7 Press left if masculine, press right if feminine, press only if $>500 \mathrm{~g}$.

8 Press left if feminine, press right if masculine, press only if $>500 \mathrm{~g}$.
Response type for the picture "Ameise (die) = ant" $(<500 \mathrm{~g}$, feminine syntactic gender $)$

\author{
concept right, syntax go \\ concept left, syntax go \\ concept right, syntax no-go \\ concept left, syntax no-go \\ syntax right, concept go \\ syntax left, concept go \\ syntax right, concept no-go \\ syntax left, concept no-go
}


Reprint requests should be sent to: Bernadette Schmitt, Department of Neurocognition, Faculty of Psychology, Maastricht University, P.O. Box 616, 6200 MD Maastricht, Netherlands, e-mail: b.schmitt@psychology.unimaas.nl.

\section{REFERENCES}

Baayen, R. H., Piepenbrock, R., \& Van Rijn, H. (1993). The CELEX lexical database. Philadelphia: Linguistic Data Consortium, University of Pennsylvania.

Bierwisch, M., \& Schreuder, R. (1992). From concepts to lexical items. Cognition, 42, 23-60.

Bock, K., \& Levelt, W. (1994). Language production: Grammatical encoding. In M. A. Gernsbacher (Ed.), Handbook of psycholinguistics (pp. 945-984). San Diego: Academic Press.

Brown, A. S. (1991). A review of the tip-of-the-tongue experience. Psychological Bulletin, 109, 204-223.

Cutler, A., \& Clifton, C. (1999). Comprehending spoken language: A blueprint of the listener. In C. Brown \& P. Hagoort (Eds.), The neurocognition of language (pp. 132-166). Oxford: University Press.

Dell, G. S. (1986). A spreading-activation theory of retrieval in sentence production. Psychological Review, 93, 283-321.

Dell, G. S. (1988). The retrieval of phonological forms in production: Tests of predictions from a connectionist model. Journal of Memory and Language, 27, 124-142.

Dell, G. S. (1990). Effects of frequency and vocabulary type on phonological speech errors. Language and Cognitive Processes, 5, 313-349.

Dell, G. S., \& O'Seaghdha, P. G. (1991). Mediated and convergent lexical priming in language production: A comment on Levelt et al. (1991). Psychological Review, 98, 604-614.

Dell, G. S., \& O'Seaghdha, P. G. (1992). Stages of lexical access in language production. Cognition, 42, 287-314.

Fuster, J. M. (1997). The prefrontal cortex: Anatomy, physiology, and neurophysiology of the frontal lobe. Philadelphia: Lippincott-Raven.

Garrett, M. (1992). Disorders of lexical selection. Cognition, 42, $143-180$.

Garrett, M. F. (1995). The structure of language processing: Neuropsychological evidence. In M. S. Gazzaniga (Ed.), The cognitive neurosciences (pp. 881-899). Cambridge: MIT Press.

Gemba, H., \& Sasaki, K. (1989). Potential related to no-go reaction of go/no-go hand movement task with color discrimination in human. Neuroscience Letters, 101, 262268.

Glaser, W. R. (1992). Picture naming. Cognition, 42, 61-105.

Jackendoff, R. (1999). The representational structures of the language faculty and their interactions. In C. Brown \& P. Hagoort (Eds.), The neurocognition of language (pp. 3779). Oxford: University Press.

Jodo, E., \& Kayama, Y. (1992). Relation of a negative ERP component to response inhibition in a go/no-go task. Electroencephalography and Clinical Neurophysiology, 82, 477-482.

Kok, A. (1986). Effects of degradation of visual stimuli on components of the event-related potential (ERP) in go/nogo reaction tasks. Biological Psychology, 23, 21-38.

Kornhuber, H. H., \& Deecke, L. (1965). Hirnpotentialänderungen bei Willkürbewegungen und passiven Bewegungen des Menschen: Bereitschafts- Potential und reafferente Potentiale [Brain potential changes associated with voluntary and passive movements in humans: Readiness potential and reafferent potentials]. Pflügers Archive, 284, 1-17.
Kutas, M., \& Donchin, E. (1974). Studies of squeezing: Handedness, responding hand, response force, and asymmetry of readiness potential. Science, 186, 545-548.

Levelt, W. J. M. (1989). Speaking: From intention to articulation. Cambridge: MIT Press.

Levelt, W. J. M., Roelofs, A., \& Meyer, A. S. (1999). A theory of lexical access in speech production. Behavioral and Brain Sciences, 22, 1-75.

Levelt, W. J. M., Schriefers, H., Vorberg, D., Meyer, A. S., Pechmann, T., \& Havinga, J. (1991a). The time course of lexical access in speech production: A study of picture naming. Psychological Review, 98, 122-142.

Levelt, W. J. M., Schriefers, H., Vorberg, D., Meyer, A. S., Pechmann, T., \& Havinga, J. (1991b). Normal and deviant lexical processing: Reply to Dell and O'Seaghdha (1991). Psychological Review, 98, 615-618.

McCarthy, G., \& Wood, C. C. (1985). Scalp distribution of event related potentials: An ambiguity associated with analysis of variance models. Electroencephalography and Clinical Neurophysiology, 62, 203-208.

Miller, J., Riehle, A., \& Requin, J. (1992). Effects of preliminary perceptual output on neuronal activity of the primary motor cortex. Journal of Experimental Psychology, Human Perception and Performance, 18, 1121-1138.

Miozzo, M., \& Caramazza, A. (1997). On knowing the auxiliary of a verb that cannot be named: Evidence for the independence of grammatical and phonological aspects of lexical knowledge. Journal of Cognitive Neurophysiology, 9, 160166.

Mulder, G., Wijers, A. A., Brookhuis, K. A., Smid, H. G. O. M., \& Mulder, L. J. M. (1994). Selective visual attention: Selective cueing, selective cognitive processing, and selective response processing. In H.-J. Heinze, T. F. Münte, \& G. R. Mangun (Eds.), Cognitive electrophysiology (pp. 26-80). Boston: Birkhäuser.

Osman, A., Bashore, T. R., Coles, M. G. H., Donchin, E., \& Meyer, D. E. (1992). On the transmission of partial information: Inferences from movement-related brain potentials. Journal of Experimental Psychology, Human Perception and Performance, 18, 217-232.

Peterson, R. R., \& Savoy, P. (1998). Lexical selection and phonological encoding during language production: Evidence for cascaded processing. Journal of Experimental Psychology, Learning, Memory, and Cognition, 24, 539-557.

Pfefferbaum, A., Ford, J. M., Weller, B. J., \& Kopell, B. S. (1985). ERPs to response production and inhibition. Electroencephalography and Clinical Neurophysiology, 60, 423-434.

Rapp, B. C., \& Caramazza, A. (1995). Disorders of lexical processing and the lexicon. In M. S. Gazzaniga (Ed.), The cognitive neurosciences (pp. 901-913). Cambridge: MIT Press.

Sasaki, K., \& Gemba, H. (1993). Prefrontal cortex in the organization and control of voluntary movement. In T. Ono, L. R. Squire, M. E. Raichle, D. I. Perrett, \& M. Fukuda (Eds.), Brain mechanisms of perception and memory: From neuron to behavior (pp. 473-496). New York: Oxford University Press.

Sasaki, K., Gemba, H., Nambu, A., \& Matsuzaki, R. (1993). Nogo activity in the frontal association cortex of human subjects. Neuroscience Research, 18, 249-252.

Schmitt, B. M., Münte, T. F., \& Kutas, M. (2000). Electrophysiological estimates of the time course of semantic and phonological encoding during implicit picture naming. Psychophysiology, 37, 473-484.

Schriefers, H., Meyer, A. S., \& Levelt, W. J. M. (1990). Exploring the time course of lexical access in language production: Picture-word interference studies. Journal of Memory and Language, 29, 86-102.

Simson, R., Vaughan, H. G., Ritter, W. (1977). The scalp topo- 
graphy of potentials in auditory and visual go/nogo tasks. Electroencephalography and Clinical Neurophysiology, 43 , 864-875.

Thorpe, S., Fize, D., \& Marlot, C. (1996). Speed of processing in the human visual system. Nature, 381, 520-522.

Tipper, S. P. T., \& Driver, J. (1988). Negative priming between pictures and words in a selective attention task: Evidence for semantic processing of ignored stimuli. Memory and Cognition, 16, 64-70.

Van Berkum, J. J. A. (1997). Syntactic processes in speech production. The retrieval of grammatical gender. Cognition, 64, 115-152.

Van Turennout, M., Hagoort, P., \& Brown, C. M. (1997). Electrophysiological evidence on the time course of semantic and phonological processes in speech production. Journal of Experimental Psychology, Learning, Memory, and Cognition, 23, 787-806.

Van Turennout, M., Hagoort, P., \& Brown, C. M. (1998). Brain activity during speaking: From syntax to phonology in 40 milliseconds. Science, 280, 572-574. 